\title{
PEMBUATAN ALAT PERAGA PEMBELAJARAN BIOLOGI BAGI GURU-GURU SMP NEGERI 22 KOTA JAMBI DAN SMP NEGERI 30 MUARO JAMBI
}

\author{
Upik Yelianti, Evita Anggereini, dan Revis Asra \\ Dosen Magister Pendidikan IPA Pascasarjana Universitas Jambi \\ Jl. Raden Mattaher no.16 Jambi \\ email: upikyelianti@ymail.com; evita_pklh@yahoo.com; r.revisasra@yahoo.com
}

\begin{abstract}
ABSTRAK
Kegiatan Pengabdian kepada masyarakat bertujuan untuk membantu para guru IPA khususnya guru biologi dalam merancang dan membuat alat peraga yang dapat digunakan dalam pembelajaran biologi di SMP. Kegiatan ini diawali dari analisis kebutuhan bahwa banyak sekolah yang tidak memiliki fasilitas laboratorium yang memadai yang menunjang proses belajar mengajar, maka alat peraga merupakan salah satu solusi dari permasalahan tersebut. Pelaksanaan kegiatan PPM di Kota Jambi dilakukan di 2 sekolah yaitu SMP N 22 dan SMP N 7 Kota Jambi yang melibatkan MGMP guru-guru IPA sebanyak 30 orang. Sedangkan kegiatan PPM di SMP N 30 Muaro Jambi hanya melibatkan guru-guru IPA dan siswa SMP N 30 serta Guru IPA SMP N 7 Muaro Jambi dengan peserta sebanyak 25 orang. Kegiatan ini diisi dengan materi: Pengenalan tentang pentingnya alat peraga dalam pembelajaran, demonstrasi serta praktek membuat alat peraga. Alat peraga yang dibuat antara lain: sistem Peredaran Darah Manusia, Sistem Eksresi, Sistem Pencernaan, dan Sistem Pernafasan pada Manusia. Kegiatan ini diikuti oleh para peserta dengan serius dan sangat antusias serta mendapatkan respon yang baik sekali. Dari kegiatan PPM ini dapat disimpulkan bahwa pembuatan alat peraga pembelajaran IPA khususnya biologi telah dilaksanakan dengan respon guru-guru yang sangat baik. Selanjutnya disarankan kepada guru-guru IPA untuk dapat menggunakan alat peraga yang telah dibuat dalam pembelajaran dan juga dapat mengembangkan alat-alat peraga IPA pada materi lainnya. Kegiatan PPM ini pada masa yang akan datang dapat juga dilakukan pada sekolah-sekolah sasaran lainnya dengan materi yang sama ataupun berbeda.
\end{abstract}

\section{Kata Kunci: Alat Peraga IPA, Pembelajaran Biologi, Guru, SMP}

\section{PENDAHULUAN}

Perbaikan kualitas pembelajaran selalu ditingkatkan oleh pemerintah melalui berbagai kegiatan dan kebijakan, antara lain melalui peningkatan kualifikasi pendidikan guru dan peningkatan sarana dan prasarana sekolah. Pada umumnya banyak sekolah yang sangat kurang sarana dan prasarana terutama peralatan laboratorium IPA khususnya Biologi. Keberadaan peralatan laboratorium IPA merupakan sarana yang harus diupayakan guna meningkatkan mutu pembelajaran IPA di sekolah. Keterbatasan sarana ini dapat dipenuhi dengan menggunakan alat peraga IPA sederhana yang bahan-bahannya mudah didapat di sekitar sekolah, tanpa mengurangi pemahaman terhadap konsep pembelajaran IPA. Oleh karena itu, Direktorat Pembinaan SMA menerbitkan buku Pedoman Pembuatan Alat Peraga IPA Sederhana untuk SMA.

Alat peraga IPA khususnya Biologi mempunyai peranan yang penting dalam pembelajaran, yaitu: a). Menjelaskan konsep, sehingga peserta didik memperoleh kemudahan 
dalam memahami hal-hal yang dikemukakan guru; b). Memantapkan penguasaan materi yang ada hubungannya dengan bahan yang dipelajari; dan c). Mengembangkan keterampilan.

Di samping peranan yang sangat penting dalam pembelajaran, alat peraga IPA/Biologi juga mempunyai fungsi yang dapat menentukan pencapaian tujuan pembelajaran IPA di sekolah, fungsi tersebut menurut Dirjen Dikdasmen Depdikbud (1999) adalah sebagai sumber belajar; metode pendidikan, sarana dan prasarana pendidikan. Menurut Badan Standar Nasional Pendidikan (BSNP, 2006), Sekolah Menengah Atas/Madrasah Aliyah (SMA/MA) harus memiliki sarana: perabot, peralatan pendidikan, media, bahan habis pakai, dan perlengkapan lainnya; serta prasarana laboratorium.

Berdasarkan hasil pengamatan di beberapa sekolah dan wawancara dengan beberapa guru mata pelajaran IPA / Biologi SMP, bahwa pada umumnya sarana dan prasarana laboratorium IPA di sekolah minim sekali. Beberapa permasalahan yang dihadapi oleh sekolah menengah, antara lain: a). Sangat minim fasilitas, alat dan bahan (zat kimia) yang ada jika dibandingkan dengan rasiojumlah pemakai laboratorium IPA; b). Adanya kecenderungan biaya yang dialokasikan sekolah untuk penunjang kegiatan laboratorium tidak mencukupi; c). Adanya kecenderungan pengguna laboratorium IPA tidak dapat menyelesaikan praktikumnya dengan baik karena waktu yang tersedia tidak mencukupi; d). Praktikum yang telah direncanakan, sering tertunda pelaksanaannya karena beberapa bahan dan alat yang tersedia jumlahnya kurang sesuai dengan kebutuhan kegiatannya; e). Belum dilakukan penataan terhadap fasilitas, alat dan bahan yang akan digunakan dalam kegiatan IPA; dan f). Penggunaan fasilitas dan peralatan yang tersedia di laboratorium IPA belum secara optimal; serta $\mathrm{g}$ ). Laboratorium kurang difungsikan secara optimal sebagai tempat melaksanakan eksperimen.

Hal ini juga diperkuat dari hasil survey yang dilakukan di SMP 24 Kota Jambi bahwa alat dan bahan praktik IPA di SMP baru sebatas digunakan dengan metode demonstrasi atau hanya diperagakan untuk beberapa topik konsep saja. SMP Negeri 22 Kota Jambi merupakan salah sekolah yang telah beberapa kali menjadi mitra tim PPM Universitas Jambi. Sekolah ini terletak sekitar $20 \mathrm{~km}$ dari Universitas Jambi, akan tetapi fasilitas laboratorium di sekolah ini sangat minim sekali. Pada tahun yang lalu tim PPM Universitas telah melakukan kegiatan PPM dengan tema: Pembuatan media pembelajaran awetan tumbuhan dan hewan. Kegiatan ini juga diikuti oleh guru dan siswa dan hasil dari kegiatan tersebut dipamerkan pada kegiatan Expo Pendidikan provinsi Jambi tahun 2015. Sekolah ini juga belum semua ruang kelas dan laboratorium dialiri listrik, sehingga penyajian materi PPt dan video pembelajaran. Oleh karena itu, diperlukan suatu kreativitas guru untuk merancang dan membuat alat peraga yang bisa membantu guru dalam menerangkan materi-materi biologi yang kebanyakan bersifat abstrak. Misalnya dalam menerangkan materi sistem peredaran darah, guru dituntut untuk dapat menerangkan sistem peredaran pendek dan sistem peredaran panjang, organ-organ yang terlibat dalam sistem peredaran darah tersebut. Demikian juga sistem eksresi dan sistem pencernaan pada manusia semuanya bersifat abstrak. Tidak bisa dipungkiri bahwa pada saat ini banyak sekali media-media elektronik yang menyajikan materi pembelajaran biologi yang dilengkapi dengan video, namun karena keterbatasan dalam sarana penunjang seperti jaringan listrik yang belum ada, kadang-kadang kalupun ada listriknya sering mati. Oleh karena itu keberadaan alat peraga sangat membantu guru dalam menyajikan konsep-konsep yang bersifat abstrak. 


\section{Permasalahan Mitra}

SMP Negeri 30 Muaro Jambi yang letaknya hanya berjarak $10 \mathrm{~km}$ dari kampus Universitas Jambi. Sekolah ini juga memiliki sarana dan prasarana laboratorium yang kurang memadai. Berdasarkan hasil pengamatan tim PPM ketika membimbing mahasiswa dalam kegiatan Praktek Pengalaman Lapangan terlihat bahwa lingkungan sekolah yang dikelelingi oleh hutan dan jauh dari lingkungan masyarakat. Di samping sarana dan prasarana laboratorium IPA yang kurang memadai, aliran listrik juga kurang memadai, sehingga penyajian materi pembelajaran berlangsung lebih menakankan kepada penggunaan buku sumber sebagai sumber belajar. Agar dapat mengurangi keterbatasan sarana dan prasarana laboratorium IPA khususnya biologi maka dilakukan suatu kegiatan PPM yang bertujuan untuk merangsang para guru untuk dapat berkreativitas mendesian dan membuat alat peraga pembelajaran IPA khususnya biologi. Dengan kegiatan ini dapat membantu guru dalam menyajikan materi pembelajaran agar konsep yang bersifat abstrak dapat dipahami oleh siswa dengan mudah.

\section{TARGET DAN LUARAN}

Target yang diharapkan dari kegiatan Pengabdian pada Masyarakat ini secara umum adalah meningkatkan pengetahuan dan keterampilan guru bidang studi IPA khusus biologi SMP dalam merancang dan mendesain alat peraga, seperti alat peraga untuk materi sistem peredaran darah dan sistem eksresi serta sistem pencernaan. Dengan memberikan pengetahuan dan keterampilan tersebut, guru-guru IPA khususnya biologi dapat merancang dan membuat alat peraga yang dapat digunakan dalam pembelajaran biologi terutama untuk materi-materi yang bersifat abstrak sehingga membantu para guru dalam menyampaikan materi pembelajaran secara aktual. Dengan adanya alat peraga ini dapat mengurangi keterbatasan sarana dan prasarana laboratorium, ruang, waktu, dan tenaga guru dalam menyediakan objek kajian yang akan diajarkan di dalam kelas.

Target dan luaran secara khusus dari kegiatan PPM ini adalah:

a. Meningkatkan pengetahuan guru-guru IPA khususnya biologi dalam pengadaan alat peraga IPA khususnya biologi, terutama alat peraga sistem peredaran darah, sistem eksresi, dan sistem pencernaan makanan pada manusia.

b. Memberikan keterampilan dalam merancang dan mambuat alat peraga IPA /biologi yang dapat digunakan guru dalam menyampaikan konsep pembelajaran di dalam kelas.

c. Meningkatkan minat guru IPA khususnya biologi dalam merakit dan membuat alat peraga pembelajaran sehingga tidak kesulitan dalam menyampaikan materi pembelajaran yang umumnya tidak tersedia setiap saat.

\section{METODE PELAKSANAAN}

\section{Mekanisme Pelaksanaan PPM}

Berdasarkan permasalahan yang telah diuraikan dan tujuan yang ingin dicapai, maka kegiatan program PPM disesuaikan dengan jadwal guru-guru dari sekolah mitra yaitu SMP N 22 Kota Jambi dan SMP N 30 Muaro Jambi. Metode pengabdian yang digunakan adalah PRA (Participatory Rural Apraisal), yaitu suatu metode pendidikan dengan melibatkan guru sebagai masyarakat khalayak sasaran sebagai subyek. Kelebihan dari metode PRA ini adalah 
melibatkan partisipasi aktif dari guru-guru sebagai khlayak sasaran yang bertindak sebagai subyek dan pihak Perguruan Tinggi sebagai fasilitator.

Kegiatan PPM ini dilakukan di dua Sekolah Menengah Pertama yaitu SMP N 22 Kota Jambi dan SMP N 30 Muaro Jambi. SMP N 30 Muaro Jambi terletak pematang Gajah Desa Mendalo Darat sekitar $10 \mathrm{~km}$ dari kampus Universitas Jambi sedangkan SMP N 22 Kota Jambi terletak di daerah Simpang Rimbo Kelurahan Kenali Besar sekitar $15 \mathrm{Km}$ dari kampus Universitas Jambi. Secara umum ke 2 SMP ini belum memiliki sarana dan prasana Alat Peraga IPA yang memadai, oleh karena itu sangat dicocok dijadikan sebagai tempat kegiatan PPM ini.

Kegiatan PPM dengan metode PAR ini terdiri dari beberapa rangkaian kegiatan yaitu: pembekalan pengetahuan (penyuluhan), pelatihan merancang dan membuat alat peraga pembelajaran IPA khususnya biologi, seperti alat peraga sistem peredaran darah, sistem eksresi, dan sistem pencernaan dengan melibatkan partisipasi aktif dari guru-guru IPA khususnya guru biologi.

a. Penyuluhan: dilakukan dalam rangka memberi pembekalan pada para guru IPA khususnya guru biologi sebagai khalayak sasaran agar dapat merancang dan membuat alat peraga IPA / biologi seperti alat peraga sistem peredaran darah, sistem eksresi, dan sistem pencernaan sehingga dapat digunakan dalam kegiatan pembelajaran di dalam kelas.

b. Pelatihan: dilakukan dengan jalan mendemonstrasikan bagaimana merancang dan membuat alat peraga pembelajaran IPA/biologi berupa seperti alat peraga sistem peredaran darah, sistem eksresi, dan sistem pencernaan. Alat perga ini dapat digunakan dalam pembelajaran metabolisme.

c. Evaluasi: monitoring dan evaluasi akan dilakukan untuk melihat tingkat ketercapaian program PPM. Evaluasi dilakukan untuk melihat apakah program ini dapat memberikan manfaat langsung bagi guru IPA dan siswa terutama dalam penyediaan media pembelajaran sehingga dapat membantu guru dalam memahamkan konsep-konsep pada anak didiknya.

\section{Materi Pembekalan}

1). Sistem eksresi:

a. alat dan bahan yang dibutuhkan dalam kegiatan PPM ini adalah: papan triplek, selotip, cairan berwarna, Gergaji triplek, gunting, pewarna, selang bening, botol plastik, cat minyak, dan model tiruan

b. Cara kerja:

- buat pola gambar ginjal dan tempel pada triplek dan warnai

- pasang selang mengikuti pola gambar sistem eksresi

- Beri label nama-nama bagain dari sistem eksresi.

- Isi cairan berwarna merah pada botol plastik untuk menunjukkan cairan darah.

2). Sistem Syaraf:

a. Alat dan bahan yang digunakan adalah: papan triplek, bola lampu, stereofom, gergaji, kabel dengan colokan listrik, bensin, spidol, dan cat warna.

b. Cara kerja:

- Potong triplek sesuai dengan kebutuhan dan buat pola sel syaraf pada triplek 
- Beri warna sesuai dengan gambar.

- Beri stereofom yang sudah dihancurkan untuk memberi kesan timbul.

- Lalu pasang bola lampu dengan colokan untuk melihat arah gerakan rangsangan.

\section{HASIL DAN PEMBAHASAN}

\section{Hasil Kegiatan}

Kegiatan Pengabdian pada Masyarakat yang berjudul: "Pembuatan Alat Peraga Pembelajaran Biologi Bagi Guru-guru SMP Negeri 22 Kota Jambi dan SMP Negeri 30 Muaro Jambi" telah dilaksanakan dalam beberapa tahapan dan beberapa sekolah. Kegiatan ini diawali dengan kunjungan tim PPM Universitas ke sekolah mitra untuk menentukan jadwal kegiatan. Kegiatan I untuk SMP Negeri 22 Kota Jambi dilakukan di SMP Negeri 7 Kota Jambi sebagai pusat MGMP Guru-guru IPA Kota Jambi, dengan melibatkan guru-guru IPA. Kegiatan II dilaksanakan di SMP Negeri 30 Muaro Jambi juga melibatkan guru-guru IPA sebanyak 5 orang ( 3 orang dari SMP N 30 dan 2 orang dari SMP N 7 Muaro Jambi) dan siswa kelas VII.

\section{1). Kegiatan PPM I untuk SMP Negeri 22 Kota Jambi}

Kegiatan PPM untuk SMP Negeri 22 Kota Jambi telah dilaksanakan di SMP Negeri 7 Kota Jambi sebagai Pusat MGMP Guru-guru IPA Kota Jambi pada hari Sabtu tanggal 01 Oktober 2016. Kegiatan ini dihadiri oleh guru-guru IPA SMP sekitar 30 orang dari berbagai sekolah di Kota Jambi. Kegiatan ini diisi dengan pemaparan materi tentang pentingnya Alat peraga dalam pembelajaran IPA dan selanjutnya dilakukan demonstrasi membuat beberapa alat peraga yang dapat digunakan dalam membantu guru-guru dalam menyampaikan materi pelajaran dalam kelas. Kemudian guru-guru membuat alat peraga secara berkelompok alat peraga dibawah bimbingan tim PPM Universitas Jambi. Materi yang disampaikan pada kegiatan PPM ini adalah: Pendahuluan, Pengertian dan Pentingnya alat peraga IPA dalam pembelajaran, Praktek membuat alat peraga IPA secara berkelompok dengan materi yang berbeda (alat peraga untuk sistem eksresi atau sistem urinaria, sistem syaraf, dan sistem peredaran darah).

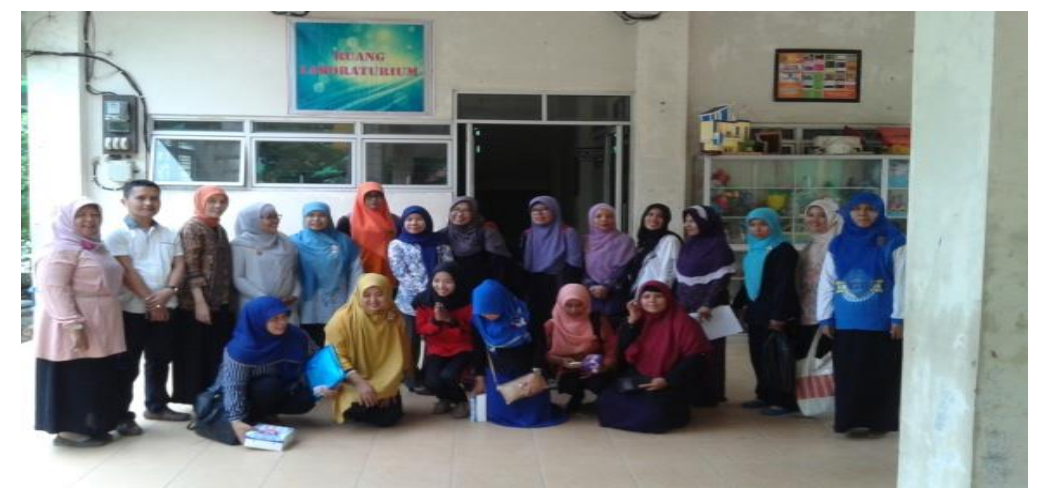

Gambar 1. Foto bersama peserta dengan Tim PPM Universitas Jambi

\section{2) Kegiatan PPM I untuk SMP Negeri 30 Muaro Jambi}

Kegiatan PPM di SMP negeri 30 Muaro Jambi ini juga diawali dengan survey untuk menetapkan jadwal dan disepakati dilaksanakan pada hari Rabu tanggal 05 Oktober 2016. 
Kegiatan ini awalnya juga ingin melibatkan guru-guru MGMP yang ada di Kabupaten Muaro Jambi, namun karena kesibukan guru-guru dalam menghadapi ujian Uji Kompetensi, maka hanya guru IPA SMP Negeri 7 Muaro Jambi yang bisa bergabung dengan guru IPA SMP N 30 Muaro Jambi beserta siswanya. Kegiatan ini juga diisi dengan materi Pentingnya alat peraga dalam pembelajaran biologi dan demonstrasi pembuatan beberapa alat peraga dan diakhir dengan pembuatan alat peraga secara berkelompok. Berikut ini disajikan foto kegiatan PPM di SMP Negeri 30 Muaro Jambi

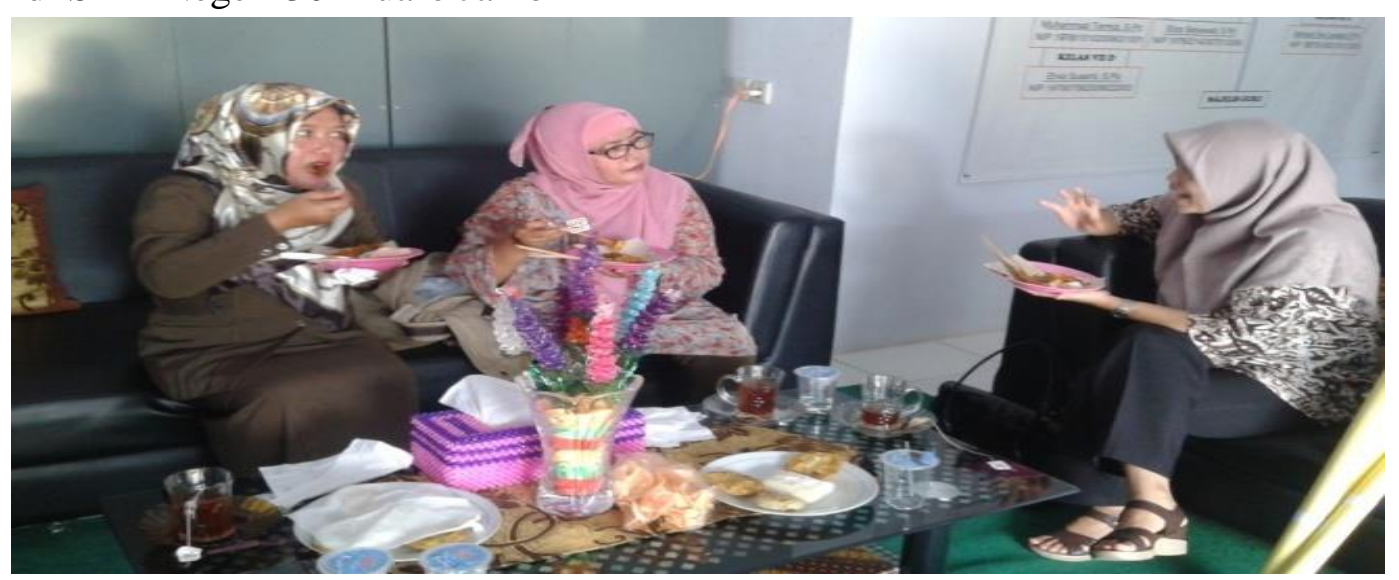

Gambar 2. Tim PPM Universitas Jambi bersama Kepala Sekolah SMP N 30 Muaro Jambi

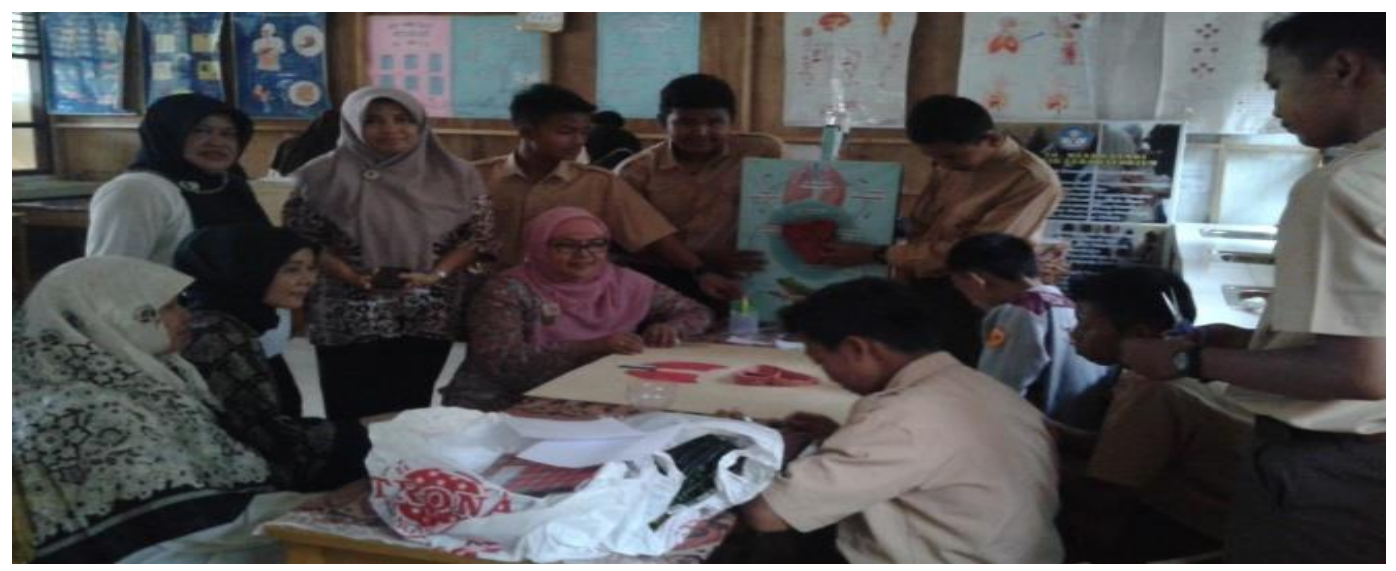

Gambar 3. Tim PPM Unja membimbing guru dan siswa SMP Negeri 30 Muaro Jambi

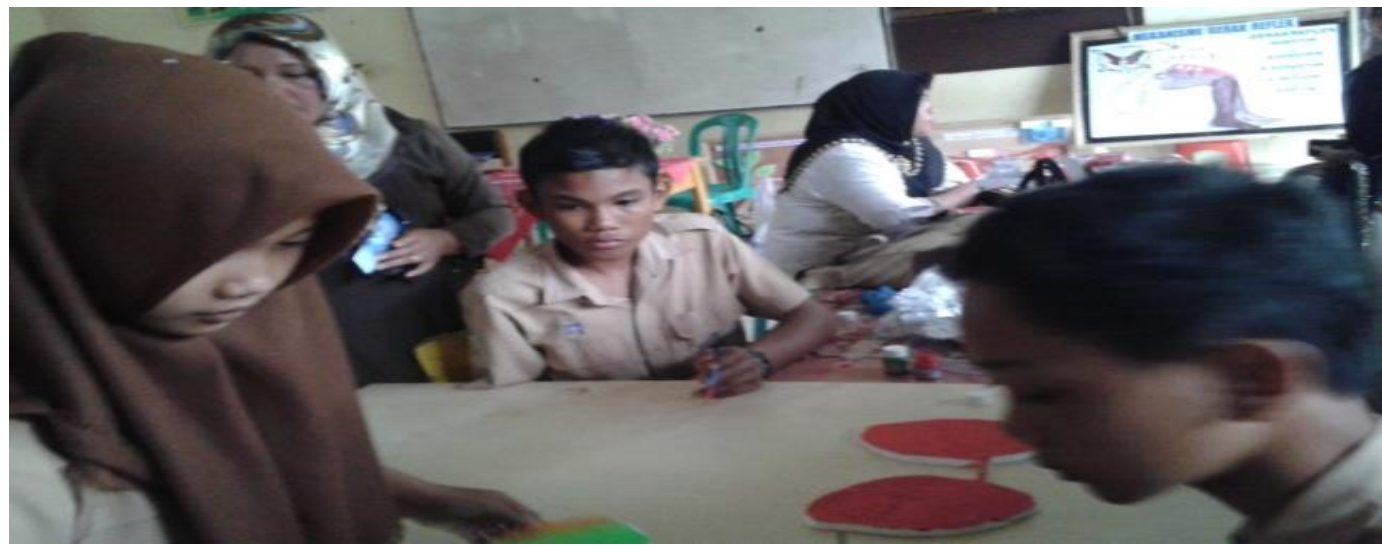

Gambar 4. Siswa membuat alat peraga biologi 


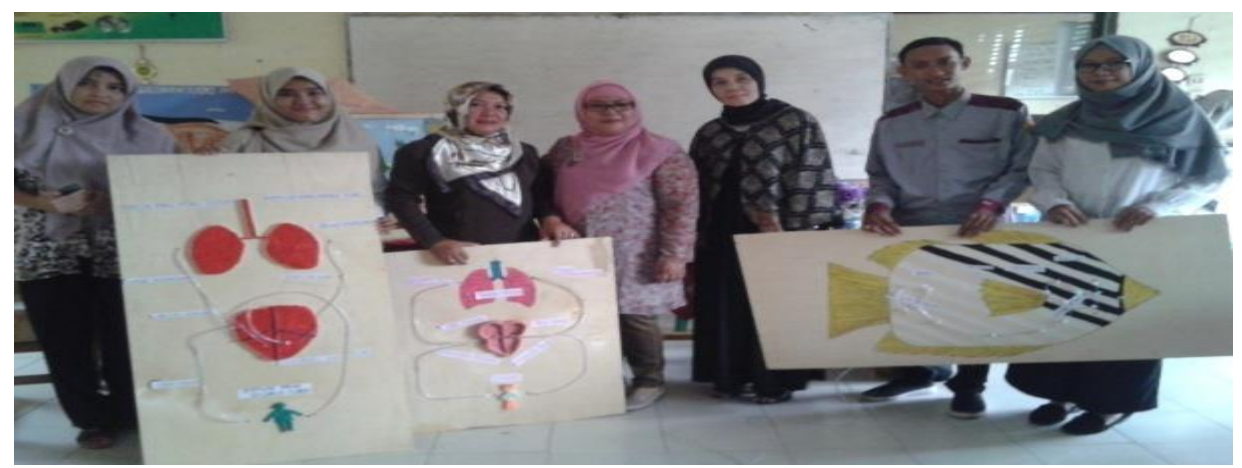

Gambar 5. Hasil karya pembuatan alat peraga guru dan siswa di SMP Negeri 30 Muaro Jambi.

Pada kegiatan PPM tentang pembuatan alat peraga IPA khususnya untuk pembelajaran biologi diikuti oleh guru-guru SMP N 22 dan Kota dan SMP N 30 Muaro Jambi dengan sangat antusias. Di SMP N 30 Muaro Jambi, kegiatan ini juga diikuti oleh siswa-siswi. Guruguru bersama siswa-siswi bekerja secara kolaborasi dalam merancang dan membuat alat peraga pembelajaran biologi. Sedangkan untuk di SMPN 22 Kota Jambi, kegiatan dilaksanakan di SMPN 7 Kota Jambi dengan melibatkan guru-guru biologi yang tergabung dalam MGMP IPA. Guru-guru sangat termotivasi dalam mendesain dan membuat alat peraga pembelajaran secara berkelompok dengan judul alat peraga yang berbeda. Alat peraga yang dibuat terdiri dari: sistem eksresi atau sistem urinaria, sistem peredaran darah, dan sistem pernafasan, serta sistem syaraf. Pada akhir kegiatan dilakukan penilaian secara umum bahwa guru-guru biologi telah mampu mendesain dan membuat alat peraga yang ditugaskan secara berkelompok pada mereka. Dengan adanya kegiatan ini diharapkan guru-guru dapat mengembangkannya pada materi lain.

\section{KESIMPULAN DAN SARAN}

\section{Kesimpulan:}

Kegiatan PPM pembuatan alat peraga biologi bagi guru-guru di SMP N 22 Kota Jambi dan SMPN 30 Muaro Jambi telah dilaksanakan, maka dapat disimpulkan sebagai berikut:

1. Guru-guru sebagai peserta merasakan bahwa kegiatan ini sangat bermanfaat karena dapat meningkatkan pengetahuan guru-guru terutama dalam membantu penyampaian materi pelajaran.

2. Guru-guru juga dapat meningkatkan keterampilan guru-guru dalam mendesain dan membuat alat peraga yang ditugaskan kepada mereka dengan baik.

3. Kegiatan ini juga membuka wawasan dan memotivasi guru-guru biologi untuk mendesain dan membuat alat peragar sesuai dengan kebutuhannya dalam mengajar di dalam kelas.

\section{Saran:}

Kegiatan PPM Universitas Jambi untuk masa mendatang dapat dilanjutkan dengan materi yang lainnya. Guru-guru IPA khususnya Biologi sangat mengharapkan kerjasama ini dapat dilanjutkan karena banyak sekolah-sekolah yang belum memiliki labor dan alat peraga pembelajaran IPA khususnya biologi. Dengan kegiatan ini dapat membuka wawasan dan 
semangat guru-guru dalam berinovasi menciptakan alat peraga pembelajaran IPA mulai dari yang sederhana sampai ke yang lebih kompleks.

\section{UCAPAN TERIMA KASIH}

Dalam kesempatan ini, perkenankan kami menghaturkan ucapan terimakasih kepada berbagai pihak yang telah membantu terlaksananya kegiatan pengabdian kepada masyarakat ini, sebagai berikut :

1. Rektor Universitas Jambi

2. Ketua LPPM Universitas Jambi

3. Direktur Pascasarjana Universitas Jambi

4. Ketua Prodi Magister Pendidikan IPA Pascasarjana Universitas Jambi

5. Kepala Sekolah dan guru-guru biologi SMP N 22 Kota Jambi

6. Kepala Sekolah dan guru-guru serta siswa SMP N 30 Muaro Jambi

7. Para mahasiswa yang terlibat dalam kegiatan pengabdian ini

8. Dan berbagai pihak yang dalam hal ini tidak dapat disebutkan satu persatu, semoga segala sesuatu yang dilakukan dalam kegiatan pengabdian ini, dapat dicatat sebagai amal ibadah di hadapan Allah SWT.

\section{DAFTAR PUSTAKA}

Arief Sidharta, Permendiknas Nomor 24 tahun 2007 tentang Standar Sarana dan Prasarana.

Arief Sidharta, Dadan Muslih.(1993). Perancangan, Pembuatan, dan Pendayagunaan Alat Peraga Praktik (APP) IPA SMP Sederhana, Jakarta: Direktorat Sarana Pendidikan

Herfen. Percobaan Biologi Sederhana. www.prestasiherfen. blogspot.com

Ridwan, M. Keuntungan Membuat Alat Peraga IPA Sederhana. Bandung: http://www.pesantrenalihsanbe.or.id

Toharudin,U.,\& Setiono. (2011). Stategi Belajar Mengajar Biologi. Bandung: Prisma Press. 